\title{
Embedding acute physicians in the emergency department to improve medical registrar training and morale
}

\author{
Authors: Carol Postlethwaite and Natalie King
}

\section{Introduction}

Much has been written about the effect that increasing workload during medical on-calls has on the medical registrar ${ }^{1,2}$ as they try to juggle safe patient treatment, their own training, supervision of their team, and often education and supervision of other doctors within the hospital, particularly on night shifts. Multiple rota gaps have negatively affected their work-life balance, as medical registrars are relied on to cover extra shifts (due to the scarcity of locum doctors), as well as the adverse effects on their training, particularly in the craft specialties (ie those with a significant amount of time performing practical procedures, eg endoscopy in gastroenterology). In places that are particularly busy, such as at East Surrey Hospital, changes in consultant working patterns to address patient flow and early senior review have inadvertently worsened the teaching and training opportunities for registrars by having multiple post-take ward rounds happening throughout the day, often simultaneously, and with different consultants taking part. These factors have colluded to create a system where our registrars are often exhausted, severely cognitively overloaded, lacking in opportunities to acquire work-based assessments (WBA) and with low morale.

\section{Methods}

To address this, and also the need to improve the time to senior review for all admitted patients towards the end of the 'day shift', a new system was devised whereby acute physicians became embedded within the emergency department ${ }^{3}$ (where the majority of the 'take' took place) to be easily available for support and advice, with predictable hours (8am-10pm weekdays), easy to contact, flexible to taking referrals or early review of patients, to debrief during or following the shift, and to complete WBAs. The 12 medical registrars on the on-call rota were surveyed at the end of the first 2 months to assess the impact that the change had had on their on-calls.

\section{Results and discussion}

$>$ All 12 registrars responded to the survey.

$>92 \%$ of respondents were aware of the change of hours.

$>75 \%$ felt that the workload had improved; none felt that it was worse.

$>$ Most felt that the extended consultant presence had improved available support during on-calls (Fig 1).

Authors: Surrey and Sussex Hospitals NHS Trust, Redhill, UK

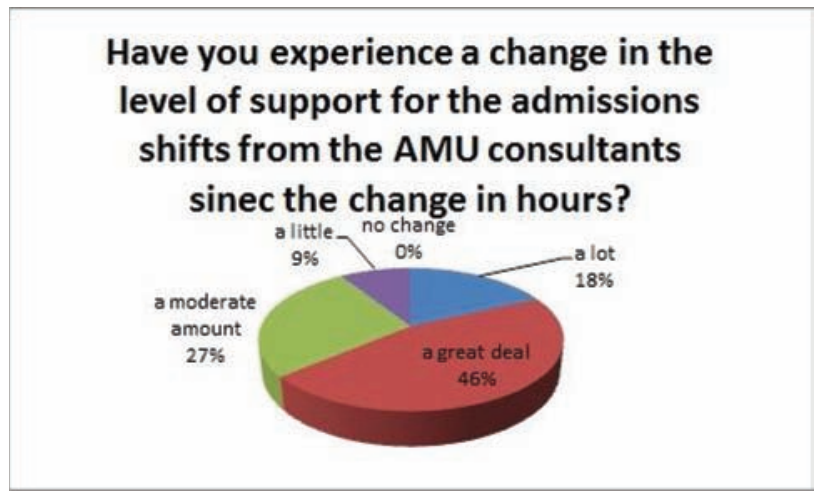

Fig 1. Responses to the survey question 'Have you experienced a change in the level of support for the admissions shifts from the AMU consultants since the change in hours?'.

> $75 \%$ were very positive or positive about access to the acute physician at the end of the night shift.

> Disappointingly, only $45 \%$ felt that it was easier to get supervised learning events performed following a night shift than under the old system.

> Most approved of acute medical unit consultants helping to take referrals during the day shift, but $9 \%$ disapproved as they liked being 'in control' of the take and that it contributed to training (Fig 2).

> However, $92 \%$ felt better supported than in the previous system.

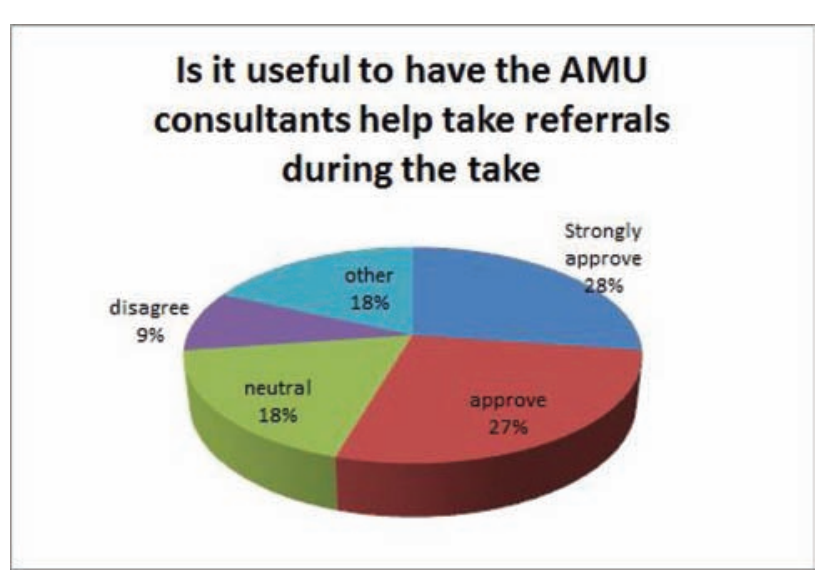

Fig 2. Responses to the survey question 'Is it useful to have the AMU consultants help take referrals during the take?'. 
Registrars' ideas for other actions that would improve training and morale included improving the staffing at busy periods, finding methods of post-take ward round that do not slow the take down, ensuring that the registrars always have a lunch break and that it is bleep free, giving immediate feedback on performance, access to non-bleep ways of communication like WiFi phones, and seeing the registrar's patients first on the take.

\section{Conclusion}

Overall this study demonstrated a very positive result, showing that embedding acute physicians outside their usual environment can be beneficial to the medical team. Work is ongoing to assess the impact on the emergency department and on patient flow.

\section{References}

1 Royal College of Physicians. Guidance on safe medical staffing. Report of a working party. London: RCP, 2018. www.rcplondon.ac.uk/projects/ outputs/safe-medical-staffing [Accessed 3 April 2019].

2 Royal College of Physicians. The medical registrar: empowering the unsung heroes of patient care. London: RCP, 2013. www.rcplondon. ac.uk/file/medical-registrar-empowering-unsung-heroes-patient-care [Accessed 3 April 2019].

3 Royal Wolverhampton Hospital NHS Trust. Senior decision makers at the front door - case study. London: NHS Improvement, 2018. https://improvement.nhs.uk/resources/senior-decision-makers-atthe-front-door/ [Accessed 3 April 2019]. 